\title{
Association of DNA-dependent protein kinase with hypoxia inducible factor-1 and its implication in resistance to anticancer drugs in hypoxic tumor cells
}

\author{
Jee Hyun Um ${ }^{1}$, Chi Dug Kang ${ }^{1}$, \\ Jae Ho Bae ${ }^{1}$, Gin Gu Shin ${ }^{1}$, Do Won Kim ${ }^{1}$, \\ Dong Wan Kim ${ }^{2}$, Byung Seon Chung ${ }^{1}$ \\ and Sun Hee $\mathrm{Kim}^{1,3}$ \\ ${ }^{1}$ Department of Biochemistry \\ College of Medicine \\ Pusan National University \\ Pusan 602-739, Korea \\ ${ }^{2}$ Department of Microbiology \\ College of Natural Sciences \\ Chang Won National University \\ Chang Won 641-773, Korea \\ ${ }^{3}$ Corresponding author: Tel, 82-51-240-7738; \\ Fax, 82-51-248-1118; E-mail, ksh7738@pusan.ac.kr
}

Accepted 16 February 2004

Abbreviations: AP1, activator protein 1 ; C/EBP- $\beta$, CAMP response element-binding protein $\beta$; DNA-PK, DNA-dependent protein kinase; Egr1, early growth response gene product 1; HIF-1, hypoxia inducible factor-1; NF-kB, nuclear factor kappa B

\begin{abstract}
Tumor hypoxia contributes to the progression of a malignant phenotype and resistance to ionizing radiation and anticancer drug therapy. Many of these effects in hypoxic tumor cells are mediated by expression of specific set of genes whose relation to therapy resistance is poorly understood. In this study, we revealed that DNA-dependent protein kinase (DNA-PK), which plays a crucial role in DNA double strand break repair, would be involved in regulation of hypoxia inducible factor-1 (HIF-1). HIF-1 $\beta$-deficient cells showed constitutively reduced expression and DNA-binding activity of $\mathrm{Ku}$, the regulatory subunit of DNA-PK. Under hypoxic condition, the expression and activity of DNAPK were markedly induced with a concurrent increase in HIF-1 $\alpha$ expression. Our result also demonstrated that DNA-PK could directly interact with HIF-1, and especially DNA-PKcs, the catalytic subunit of DNA-PK, could be involved
\end{abstract}

in phosphorylation of HIF-1 $\alpha$, suggesting the possibility that the enhanced expression of DNA. PK under hypoxic condition might attribute to modulate HIF-1 $\alpha$ stabilization. Thus, the correlated regulation of DNA-PK with HIF-1 could contribute to therapy resistance in hypoxic tumor cells, and it provides new evidence for developing therapeutic strategies enhancing the efficacy of cancer therapy in hypoxic tumor cells.

Keywords: DNA-PK; drug resistance; HIF-1; hypoxia Introduction

\section{Introduction}

Hypoxia, a reduction of oxygen tension below the normal level for a tissue, plays an important role in development of tumor cells (Brahimi-Horn et al., 2001; Goonewardene et al., 2002). Tumor cells undergo genetic and adaptive changes such as increased expressions of hypoxia-inducible factor-1 (HIF-1), NF-kB, AP-1, C/EBP- $\beta$ and Egr-1, which allow them to survive and even proliferate in a hypoxic environment, and thus a wide range of gene expressions is induced by hypoxia (Koong et al., 1994; Yao et al., 1994; Yan et al., 1997; Yan et al., 1999; Harris, 2002; Joung et al., 2003).

HIF-1 is a heterodimer that consist of HIF- $1 \alpha$, which is tightly regulated by oxygen concentration, and HIF-1 $\beta$, which is a constitutively expressed aryl hydrocarbon receptor nuclear translocator (ARNT). In the absence of oxygen, HIF-1 $\alpha$ forms an active complex with HIF-1 $\beta$ and binds to hypoxia-response element (HRE), thereby activating the expression of numerous hypoxia-responsible genes.

Tumor hypoxia contributes to the progression of a more malignant phenotype by selecting for cells with a diminished apoptotic potential, and the hypoxic cells are intrinsically more resistant to radiotherapy and chemotherapy based on cell killing effect in welloxygenated cells (Brown, 2000; Harris, 2002; Wouters et al., 2002). In fact, HIF-1 $\alpha$ was overexpressed in colon, breast, gastric, lung, skin, ovarian, pancreatic and renal carcinomas and associated with cell proliferation and poor prognosis (Zhong et al., 1999), and the elevated level of HIF-1 is closely correlated with radioresistant and aggressive disease in oropharyngeal cancer (Aebersold et al., 2001). HIF-1 $\alpha$ deficient 
cells are more susceptible to anticancer drug and ionizing radiation (Unruh et al., 2003), and also Pglycoprotein (P-gp), the multidrug resistance (MDR) gene product, is regulated by HIF-1 (Comerford et al., 2002; Wartenberg et al., 2003), suggesting that HIF-1 expression could be involved in development of chemoresistance and radioresistance. However, mechanisms underlying therapy resistance of hypoxic cells are multifactorial and not fully understood.

Previously, it has been reported that the expression of DNA-dependent protein kinase (DNA-PK) is associated with resistance against chemotherapeutic agents such as adriamycin and chlorambucil (Christodoulopoulos et al., 1998; Muller et al., 1998; Shen et al., 1998) and participated in the development of MDR (Kim et al., 2000; Um et al., 2001). Also, the increased expression and activity of DNA-PK are essential for cellular resistance to ionizing radiation in human tumor cells (Kienker et al., 2000; Ader et al., 2002; Marples et al., 2002; Shintani et al., 2003; Soubeyrand et al., 2003).

The DNA-PK is formed by association of the 460$\mathrm{kDa}$ catalytic subunit (DNA-PKcs) with a DNA binding subunit known as $\mathrm{Ku}$, a heterodimer of $70-\mathrm{kDa}$ (Ku70) and $86-\mathrm{kDa}(\mathrm{Ku} 80)$, and the enzyme plays a role in repair of DNA double-strand breaks (DSBs) and single strand nick and gap (Gottlieb and Jackson, 1993; Morozov et al., 1994; Jeggo, 1997; Jin et al., 1997; Kim et al., 2002). Defects in DNA-PK subunit have shown to result in a reduced capacity to DNA DSBs repair and consequently a hypersensitivity to radiation (Lees-Miller et al., 1995; Gu et al., 1997) and etoposide, a DNA-damaging agent (Jin et al., 1998).

Recently, it has been shown that DNA repair pathways involved in DNA DSBs repair likely include potential HIF-1 target (Unruh et al., 2003), and also the expression of Ku70 or Ku80 is up-regulated by hypoxia in several cells (Ginis and Faller, 2000; Lynch et al., 2001), suggesting that DNA-PK might be involved in regulation of HIF-1.

Therefore, in the present report, the modulation of DNA-PK and its role on HIF-1 expression were investigated under hypoxic condition, one of the most basic environmental stresses that cancer cells may experience. Our results showed that HIF-1 $\alpha$ expression was positively correlated with the expression of DNA-PK, which could contribute to radioresistance and chemoresistance in hypoxic tumor cells. This is the first report that demonstrates a new role of DNA-PK on HIF-1 regulation.

\section{Materials and Methods}

\section{Cell Lines and hypoxic conditions}

Human hepatoma HepG2 cell line was grown in
Dulbecco's modified Eagle's medium (DMEM, GIBCO Invitrogen Corp., Carlsbad, CA) containing 10\% (v/v) fetal bovine serum (FBS) (GibcoGIBCO Invitrogen Corp., Carlsbad, CA), streptomycin $(100 \mu \mathrm{g} / \mathrm{ml})$, and penicillin $(100 \mathrm{U})$. Mouse hepatoma HepaC1C7 cells and its HIF-1 $\beta$-deficient HepaC4 cells (Maxwell et al., 1997; Griffiths et al., 2002) were cultured in DMEM with $10 \%(\mathrm{v} / \mathrm{v})$ FBS and antibiotics. Murine embryonic fibroblast MEF and its Ku-deficient $\mathrm{Ku} 70^{-1-}$ cells immortalized by SV40 transfection were maintained in DMEM supplemented with $10 \%$ (v/v) FBS and antibiotics. DNA-PKCS deficient SCID cells and isogenic wild type murine embryonic fibroblast CB-17 cells were maintained in DMEM supplemented with $10 \%$ (v/v) FBS and antibiotics.

The cells were subjected to normoxia in a humidified atmosphere containing $5 \% \quad \mathrm{CO}_{2}$ level with $20 \% \mathrm{O}_{2}(\mathrm{v} / \mathrm{v})$ at $37^{\circ} \mathrm{C}$. For the hypoxic condition, cells were incubated at $5 \% \quad \mathrm{CO}_{2}$ level with $1 \% \mathrm{O}_{2} \quad(\mathrm{v} / \mathrm{v})$ balanced with $\mathrm{N}_{2}$ gas. Deferoxamine (DFX, Sigma Co.) was treated as mimic hypoxic condition (Wood et al., 1996).

\section{Cell extract preparation and electrophoretic mobility shift assay (EMSA)}

Nuclear extracts were prepared from normoxic or hypoxic cells as described previously (Shintani et al., 2003). In brief, $3 \times 10^{6}$ cells were washed with cold phosphate buffered saline and harvested quickly and resuspended in $300 \mathrm{ml}$ of lysis buffer [10 mM HEPES, $\mathrm{pH} 7.9,1.5 \mathrm{mM} \mathrm{MgCl} 2,10 \mathrm{mM} \mathrm{KCl}, 0.5 \mathrm{mM}$ dithiothreitol (DTT), $0.5 \mathrm{mM}$ phenylmethylsulphonyl fluoride (PMSF)]. The cells allowed swelling in ice for $10 \mathrm{~min}$. After $0.05 \%$ Nonidet P40 was added, the tube was vigorously mixed 3 times for $3 \mathrm{~s}$ on a vortex, and centrifuged at $250 \times \mathrm{g}$ for $10 \mathrm{~min}$ to pallet the nuclei. The nuclear pellet was resuspened in $30 \mathrm{ml}$ of ice-cold nuclear extraction buffer (5 mM HEPES, $\mathrm{pH}$ 7.9 , and $26 \%$ glycerol (v/v), $1.5 \mathrm{mM} \mathrm{MgCl}_{2}, 0.2 \mathrm{mM}$ EDTA, $0.5 \mathrm{mM}$ DTT, $0.5 \mathrm{mM}$ PMSF) and then incubated on ice for $30 \mathrm{~min}$ with intermittent mixing, and centrifuged at $24,000 \mathrm{~g}$ for $20 \mathrm{~min}$ at $4^{\circ} \mathrm{C}$. The nuclear extract was either used immediately or stored at $-70^{\circ} \mathrm{C}$ for later use. $10 \mu \mathrm{g}$ of nuclear extract was incubated with ${ }^{32} \mathrm{P}$-labeled double-stranded oligonucleotide, 5'-AGTTGAGGGGACTTTCCCAGGC-3' for $\mathrm{Ku}$ binding and ${ }^{32} \mathrm{P}$-labeled HRE consensus oligonucleotide, 5'-TCTGTACGTGACCACACTCACCTC-3' (Santa Cruz Biotechnology, Inc., Santa-Cruz, CA) in binding buffer (10 mM Tris- $\mathrm{HCl}, \mathrm{pH} 7.9,50 \mathrm{mM} \mathrm{NaCl}$, $1 \mathrm{mM} \mathrm{MgCl}, 0.5 \mathrm{mM}$ EDTA, $4 \%$ glycerol) containing $50 \mu \mathrm{g} / \mathrm{ml}$ of poly $(\mathrm{dl}-\mathrm{dC})$. The DNA-protein complex was separated from free oligonucleotide on $4 \%$ nondenaturing polyacrylamide gel using $0.5 \times T B E$ buffer (44.4 mM Tris- $\mathrm{HCl}, \mathrm{pH} 8.0,44.5 \mathrm{mM}$ boric acid, 1 
$\mathrm{mM}$ EDTA) for $3 \mathrm{~h}$ at $120 \mathrm{~V}$. The gels were dried and autoradiographed (Byun et al., 2002). For supershift assay, $1 \mu \mathrm{g}$ of monoclonal antibody specific to Ku70, HIF- $1 \alpha$, HIF-1 $\beta$ or CBP was incubated with nuclear extracts for $2 \mathrm{~h}$ at $4^{\circ} \mathrm{C}$ prior to the DNA shift assay.

\section{Western blot analysis}

Whole cell lysates or nuclear extract containing an equal amount of protein were separated by SDSPAGE and blotted to nitrocellulose membrane (HybondECL, Amersham Biosciences, Buckinghamshire, England). The membrane was incubated with antibody as specified, followed by secondary antibody conjugated with horseradish peroxidase. Specific antigen-antibody complexes were detected by enhanced chemiluminescence (Pierce Biotechnology, Inc., Rockford, IL). The following antibodies were used in these studies. The antibodies to HIF-1 $\beta, \mathrm{Ku} 70 / 80$, and CBP were obtained from (Santa Cruz Biotechnology, Inc., Santa-Cruz, CA) and the anti-DNA-PKcs, and anti-HIF1 $\alpha$ antibodies were obtained from Neomarker (Lab Vision Corp., Fremont, $\mathrm{CA})$. Secondary antibodies were obtained from Amersham Biosciences, Buckinghamshire, England.

\section{Immunoprecipitation assay}

For immunoprecipitation, nuclear extracts from HepaC1C7 cells treated with DFX or hypoxia for $4 \mathrm{~h}$ were incubated with antibody to HIF-1 $\alpha$, HIF-1 $\beta$, Ku70, Ku80, CBP or DNA-PKcs for overnight at $4^{\circ} \mathrm{C}$. Then protein G-Sepharose beads (Sigma-aldrich Corp., ST Louis, MO) were added and constantly mixed for 4 h. The beads were collected by centrifugation for 5 min at $12,000 \mathrm{rpm}, 4^{\circ} \mathrm{C}$ and washed three times with cold extraction buffer. The beads with immunocomplexes were boiled and electrophoresed on $8 \%$ SDSpolyacrylamide gels and analyzed by Western blotting.

\section{Growth inhibition assay}

Cells were seeded in 96 well plates at $4 \times 10^{3}$ cells/ well and treated with 5-, $10 \mu \mathrm{M}$ DFX for $6 \mathrm{~h}$, before VP-16 was added for $96 \mathrm{~h}$. Growth inhibition was assessed by MTT assay. Briefly, following treatment of the cells, the medium was replaced with fresh medium containing $500 \mu \mathrm{g} / \mathrm{ml}$ MTT [3-(4,5-dimethyl-2thiazolyl)-2,5-diphenyl-2H-tetrazolium bromide] solution and the plates were incubated in the dark room for $4 \mathrm{~h}$. The water-insoluble MTT-formazan crystals were dissolved in dimethyl sulfoxide, and reduction of MTT was determined at $570 \mathrm{~nm}$ using ELISA reader (BioTec Instruments, Inc., Winooski, VT). The concentration of each anticancer drug, which reduced cell growth rate by $50 \%$ after $96 \mathrm{~h}$ treatment $\left(\mathrm{IC}_{50}\right)$, was determined from the growth inhibition plots.

\section{DNA-dependent protein kinase assay}

The kinase activity of DNA-PK was determined using the Signa TECT ${ }^{\mathrm{TM}}$ DNA-dependent Protein Kinase Assay System from Promega Corp., Madison, WI. In brief, $10 \mu \mathrm{g}$ of nuclear extract was incubated with activator DNA, a biotinylated p53-derived peptide substrate, and $\left[\gamma^{32} \mathrm{P}\right] \mathrm{ATP}$ at $30^{\circ} \mathrm{C}$ for $5 \mathrm{~min}$. The sample was terminated by adding termination buffer. Each termination reaction sample was spotted onto $\mathrm{SAM}^{2 \mathrm{TM}}$ Biotin Capture Membrane and washed with $2 \mathrm{M} \mathrm{NaCl}$ and $2 \mathrm{M} \mathrm{NaCl}$ in $1 \% \mathrm{H}_{3} \mathrm{PO}_{4}$. The $\mathrm{SAM}^{2 \mathrm{TM}}$ Membrane squares were analyzed using Molecular Imager System (Bio-Rad Laboratories, Inc., Model GS 525, Hercules, CA).

\section{Results}

\section{Involvement of HIF-1 in $\mathrm{Ku}$ regulation}

Since previous reports have shown that HIF-1 and NF- $\mathrm{BB}$ are corporatively activated under hypoxic condition (Jeong et al., 2003), and Ku, regulatory subunits of protein kinase, activity is closely correlated with NF-kB activity (Um et al., 2001; Lim et al., 2002), $\mathrm{Ku}$ and NF-KB activities in mouse hepatoma HepaC1C7 cell and its HIF-1 $\beta$-deficient HepaC4 cells, which is unable to form a functional HIF-1 complex, were analyzed by EMSA. As shown in Figure 1, HepaC4 cells showed constitutively reduced DNAbinding activities of $\mathrm{Ku}$ and $\mathrm{NF}-\mathrm{KB}$ compared with those of wild type HepaC1C7 cells, and it resulted from reduced basal expressions of Ku70/80 and NF-KB p65. These results suggested that HIF-1 could affect the regulation of $\mathrm{Ku}$.

To determine whether $\mathrm{Ku}$ expression and its activity could be modulated under hypoxic condition, $\mathrm{Ku}$ expression and its activity of HepG2 cells exposed to hypoxia and $\mathrm{HepaC} 1 \mathrm{C} 7$ cells treated with deferoxamine (DFX), the hypoxia mimicking chemical, were examined (Figure 2). The expression and activity of $\mathrm{Ku}$ were markedly increased in these cells under hypoxic condition with a concurrent increase in HIF- $1 \alpha$ in a time-dependent manner. These results suggest that $\mathrm{Ku}$ expression and its activity are upregulated with a concurrent increase in hypoxiainduced HIF-1 $\alpha$ expression.

\section{Deficiency of DNA-PK component resulted in down-regulation of HIF-1}

To elucidate the correlation between the regulation of HIF-1 and $\mathrm{Ku}$, the level of HIF-1 expression was examined in the Ku-deficient $\mathrm{Ku} 70^{-/}$cells and their wild type MEF under hypoxic condition using DFX treatment. As shown in Figure 3, the expression of HIF- $1 \alpha$ of MEF cells was strongly induced as early 
A

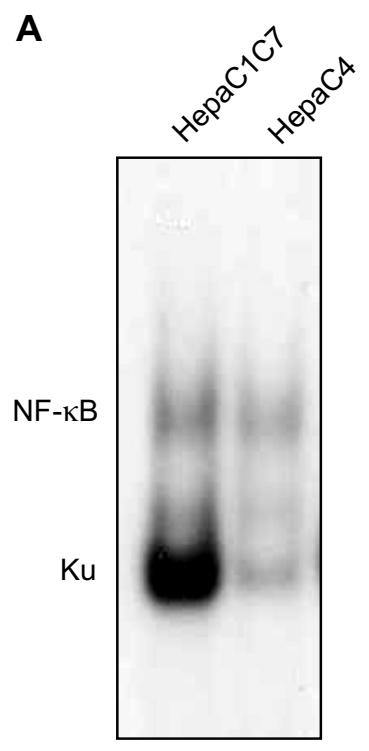

B

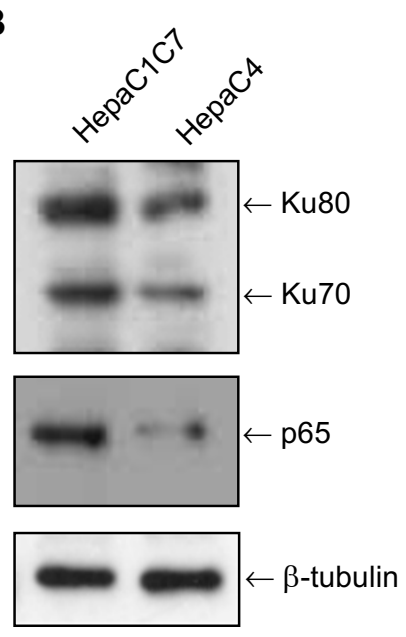

Figure 1. Reduced activity and expression of $\mathrm{Ku}$ and NF-KB in HIF-1 $\beta$ deficient HepaC4 cells. (A) Nuclear extracts isolated from $\mathrm{HepaC} 4$ cells and its wild type $\mathrm{HepaC1C7}$ cells were analyzed for $\mathrm{Ku}$ and NF-kB DNA-binding activities by EMSA. (B) Nuclear expression levels of NF-KB p65 and Ku70/80 in HepaC4 and $\mathrm{HepaC1C7}$ cells were evaluated by Western blot analysis. $\beta$-tubulin level was shown as reference control.
A HepG2
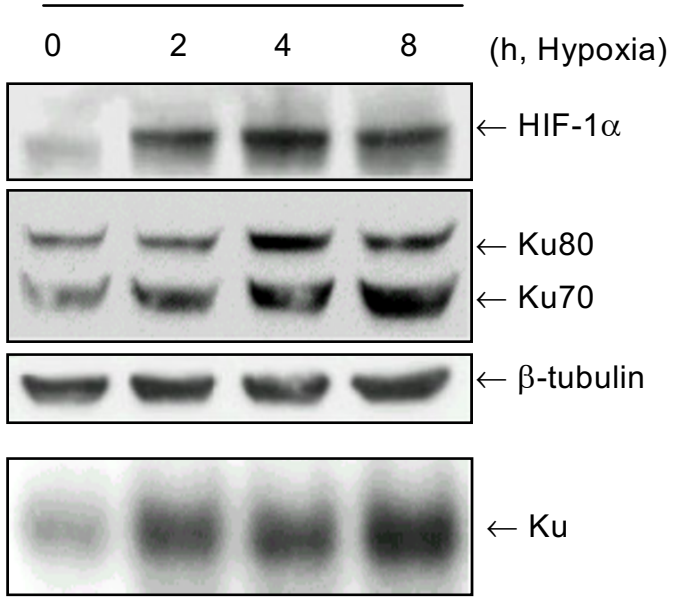

B
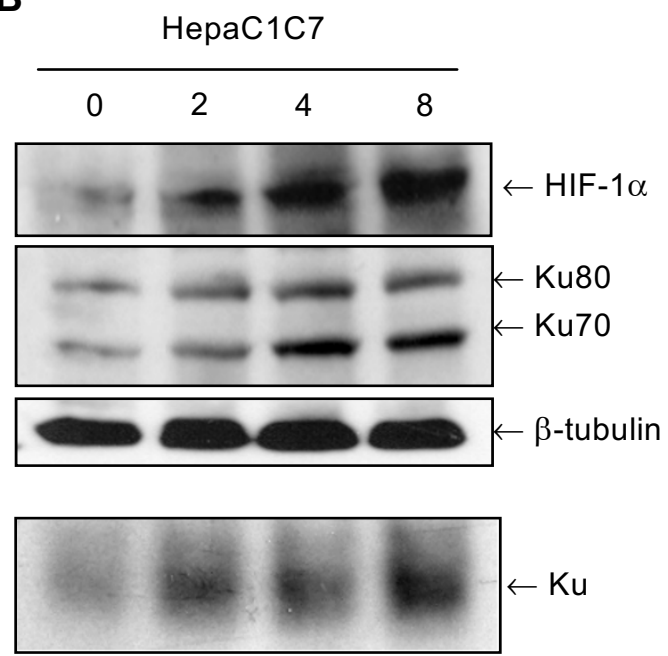

Figure 2. Enhanced Ku activity and its expression level under hypoxic condition. HepG2 cells were exposed to hypoxia (94\% $\mathrm{N}_{2}, 5 \% \mathrm{CO}_{2}, 1 \% \mathrm{O}_{2}$ ) for the indicated time. (A) HepaC1C7 cells were treated with $260 \mu \mathrm{M}$ deferoxamine (DFX) for the indicated time. (B) Western blot analysis was carried out to measure the expression levels of HIF-1 $\alpha$ and Ku70/80. $\beta$-tubulin was used to show relative expression and loading difference (top and middle panels). Nuclear extracts of these cells were prepared and subjected to EMSA for Ku DNA-binding activity (bottom panel).

MEF

\begin{tabular}{|c|c|c|c|c|c|c|c|c|}
\hline 0 & 2 & 4 & 8 & 0 & 2 & 4 & 81 & , DFX) \\
\hline- & $=$ & 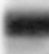 & 5. & 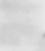 & $=$ & tis & 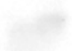 & $-\mathrm{HIF}-1$ \\
\hline
\end{tabular}

Figure 3. Modulation of HIF-1 in Ku-deficient cells. Ku-deficent Ku70-1 cells and their wild type MEF cells were treated with $260 \mu \mathrm{M}$ DFX for the indicated time. Nuclear extracts were prepared, and Western blot analysis was performed using anti-HIF-1 $\alpha$ and anti-HIF-1 $\beta$. as at $2 \mathrm{~h}$ and maximized at $4 \mathrm{~h}$ but that of $\mathrm{Ku} 70^{-/-}$ cells was markedly reduced in under same hypoxic condition. Also, the expression of HIF-1 $\beta$ in MEF cells was increased during $2-4 \mathrm{~h}$ but that in $\mathrm{Ku}^{-/-}$cells was transiently increased at $4 \mathrm{~h}$ under same hypoxic condition. These results suggest that intracellular level of $\mathrm{Ku}$ could affect the regulation of HIF-1 expression.

To test the hypothesis that DNA-PKcs may affect on the HIF-1 regulation, the modulation of HIF-1 expression by DNA-PKcs under hypoxic condition was investigated. HepaC1C7 cells were exposed to hy- 
A

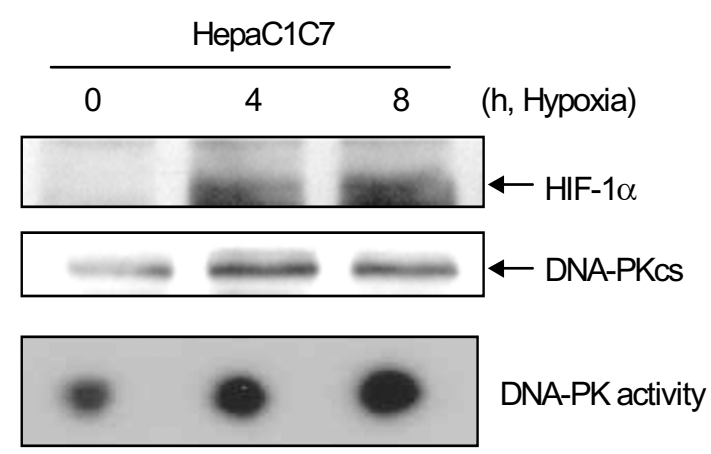

B

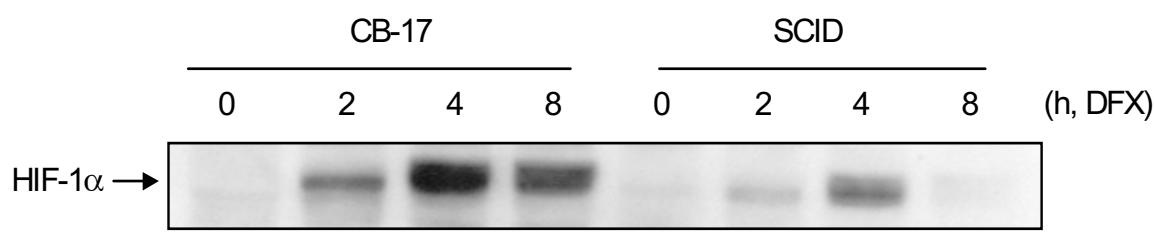

C

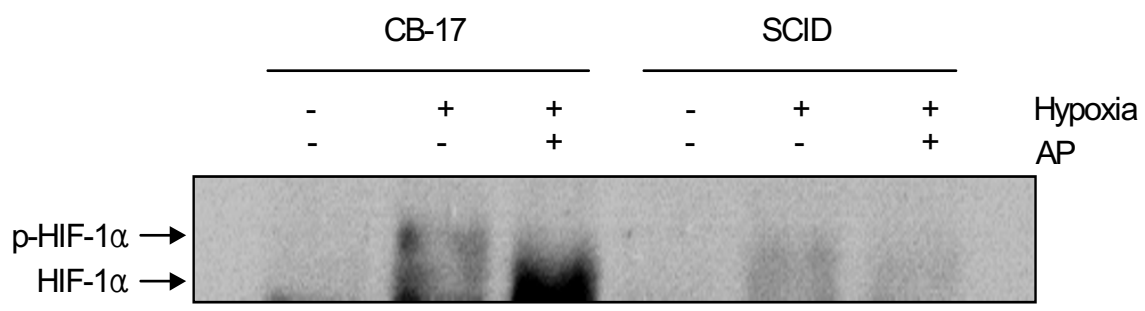

Figure 4. Effect of hypoxia on DNA-PKcs and DNA-PK activity, and the modulation of the expression and phosphorylation of HIF-1 $\alpha$ by the expression of DNA-PKcs. Nuclear extracts were isolated from HepaC1C7 cells exposed to hypoxia for the indicated time. HIF-1 $\alpha$ and DNA-PKcs expression was analyzed by Western blotting (A, top and middle panels), and DNA-PK activity was measured as described in Material and Method (A, bottom panel). CB-17 and SCID cells were treated with $260 \mu \mathrm{M}$ DFX for the indicated time. Nuclear extracts were isolated and subjected to Western blot analysis to measure HIF-1 $\alpha$ expression level (B) Nuclear extracts from CB-17 cells and SCID cells exposed to hypoxia for $4 \mathrm{~h}$ were incubated without or with alkaline phosphatase (AP) at $37^{\circ} \mathrm{C}$ for $2 \mathrm{~h}$, and HIF-1 $\alpha$ protein level was analyzed by Western blotting using anti-HIF-1 $\alpha$ antibody (C).

poxia, and the changed levels of HIF-1 $\alpha$ and DNAPKcs were determined. As shown in Figure 4A (top and middle panels), the HIF-1 $\alpha$ expression was markedly increased consistent with an increase of DNA-PKcs expression under hypoxia. Therefore, to examine whether the up-regulated $\mathrm{Ku}$ and DNA-PKcs expression under hypoxia could lead to increase the activity of whole DNA-PK complex, the DNA-PK activity was analyzed. As expected, the DNA-PK activity was significantly increased under hypoxia in a time dependently (Figure 4A, bottom panel), suggesting that DNA-PK activity could be correlated with HIF-1 $\alpha$ expression.

To confirm the involvement of DNA-PKcs in HIF-1 regulation, the expression of HIF-1 $\alpha$ of DNA-PKcsdeficient SCID cells was compared with that of parental CB-17 cells. The expression of HIF- $1 \alpha$ was examined in SCID and CB-17 cells treated with DFX for the indicated time (Figure 4B). Under hypoxic condition, the HIF- $1 \alpha$ expression of SCID cells was markedly down-regulated as compared to that of CB-17 cells, whose HIF-1 $\alpha$ expression was rapidly induced at $2 \mathrm{~h}$, reaching a peak at $4 \mathrm{~h}$, suggesting that the DNA-PKcs may be positively correlated with HIF-1 regulation. Curiously, in this data, the mobility of HIF-1 $\alpha$ migration was slower in CB-17 cells than in SCID cells. It has been demonstrated that the migration of phosphorylated protein can slow down on SDS-polyacrylamide gels as compared to unphosphorylated protein (Richard et al., 1999). Thus, to examine whether slowly moving HIF-1 $\alpha$ protein of CB-17 cells could be resulted from phosphorylation, the nuclear extracts from CB-17 cells and SCID cells exposed to hypoxia for $4 \mathrm{~h}$ were treated with alkaline 
phosphatase. As shown in Figure 4C, slowly moving HIF-1 $\alpha$ could become unphosphorylated form in CB-17 cells by phosphatase, whereas no remarkable difference of HIF- $1 \alpha$ by phosphatase was found in SCID cells. These results suggest the possibility that DNA-PK could be participated in the phosphorylation of HIF- $1 \alpha$ and activate HIF-1 $\alpha$ under hypoxia.

\section{Interaction between HIF-1and DNA-PK components}

To test the direct interaction between HIF-1 and DNA-PK components, HepaC1C7 cells were treated with DFX, and the nuclear extracts were immunoprecipitated with antibody against Ku70 or Ku80. The co-immunoprecipitated proteins were resolved on a polyacrylamide gel and proteins were detected by immunoblotting using anti-HIF-1 $\alpha$ antibody. HIF-1 $\alpha$ was detected in the immunoprecipitated proteins with anti-Ku70 or anti-Ku80 antibody (Figure 5A, left two panels). Since it is mandatory to form heterocomplex with HIF- $1 \alpha$ and HIF-1 $\beta$ for HIF-1 function, we carried out immunoprecipitations with antibodies against Ku80 and immunoblotted with an antibody against HIF-1 $\beta$ to examine whether HIF-1 $\beta$ was present in $\mathrm{Ku}$ immunoprecipitates. HIF-1 $\beta$ was detected in the immunoprecipitated proteins with anti-Ku80 antibody (Figure 5A, middle panel). Conversely, the nuclear extracts of HepaC $1 \mathrm{C} 7$ cells treated with DFX were immunoprecipitated with antibody against HIF-1 $\alpha$. Ku70 and Ku80 were detected in the immunoprecipitated proteins with anti-HIF-1 $\alpha$ antibody (Figure $5 \mathrm{~A}$, right panel), suggesting that the Ku component of DNA-PK could interacted with HIF-1 components.

We next examined whether DNA-PKcs could interact with HIF-1 $\alpha$ under hypoxic condition. The nuclear extracts of HepG2 cells exposed to hypoxia for $4 \mathrm{~h}$ were incubated with anti-DNA-PKcs antibody. HIF-1 $\alpha$ was detected in the immunoprecipitated proteins with anti-DNA-PKcs antibody (Figure 5B). These results indicate that DNA-PK complex could physically interact with HIF-1 complex including HIF- $1 \alpha$ and HIF-1 $\beta$.

To confirm further the association of HIF-1 and Ku complex, the supershift assay using anti-Ku70 antibody was performed with nuclear extracts from HepaC $1 C 7$ cells treated with DFX. As shown in Figure 6A, DFX-induced DNA binding activity of HIF-1 was supershifted by anti-Ku70 antibody (lane 5) and anti-CBP antibody, which was used as a positive control (lane 3) due to binding with HIF-1 during transcriptional activation. Conversely, the $\mathrm{Ku}$ DNA binding activity induced by hypoxia was supershifted by antibody to HIF- $1 \alpha$, HIF-1 $\beta$ or CBP (Figure $6 \mathrm{~B}$. lane $3,4,5$ and 6$)$. These results provide strong evidence that $\mathrm{Ku}$ contributes formation of HIF-1 binding complex.

HIF-1 $\beta$-deficiency affects cellular susceptibility to chemotherapeutic agent and the mimic of hypoxia

From the result shown above, HIF-1 expression can be up-regulated with a concurrent increase in DNA-
A

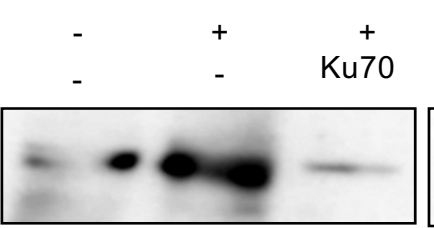

(WB: HIF-1 $\alpha$ )

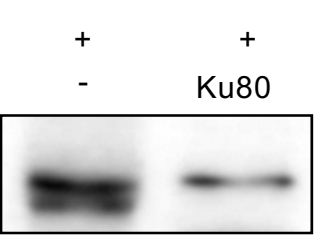

(WB: HIF-1 $\alpha$ )

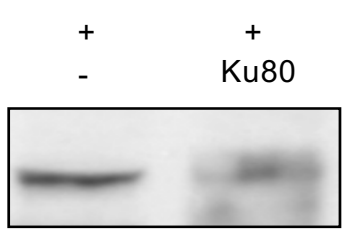

(WB: HIF-1 $\beta$ )

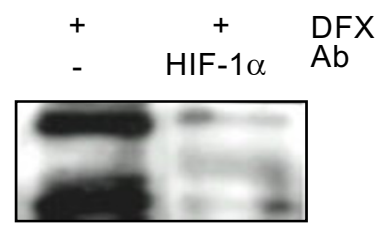

(WB: Ku70/80)

B

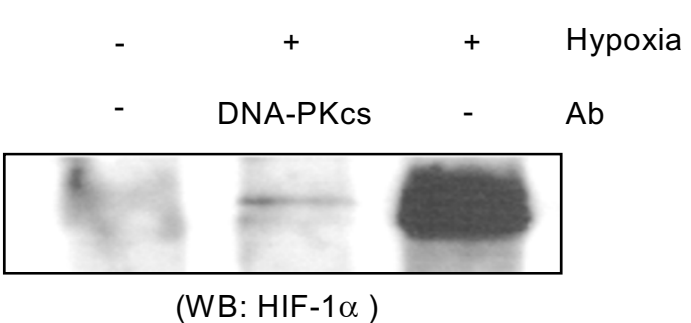

Figure 5. Interaction between HIF-1 and DNA-PK complex. HepaC1C7 cells were treated with $260 \mu \mathrm{M}$ DFX for $4 \mathrm{~h}$ and the nuclear extracts were immunoprecipitated with anti-Ku70, anti-Ku80 or HIF-1 $\alpha$ antibody. The co-immunoprecipitated proteins were resolved on a polyacrylamide gel and proteins were detected by Western blotting using anti-HIF-1 $\alpha$, anti-HIF-1 $\beta$ or anti-Ku70/80 antibody (A) HepG2 cells were exposed to hypoxia for $4 \mathrm{~h}$, and the nuclear extracts were immunoprecipitated with anti-DNA-PKcs antibody. The immunoprecipitates were resolved in SDS-PAGE, and Western blotting was carried out using anti-HIF-1 $\alpha$ antibody (B). 
A

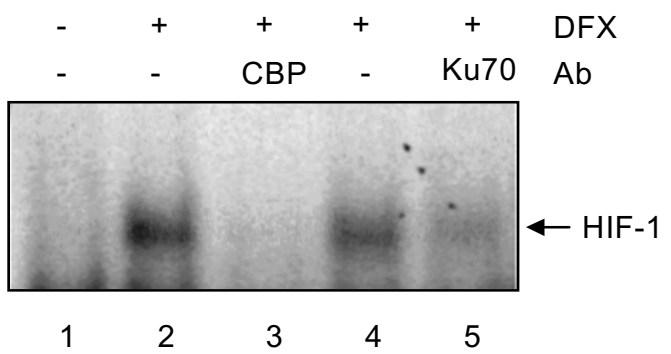

B

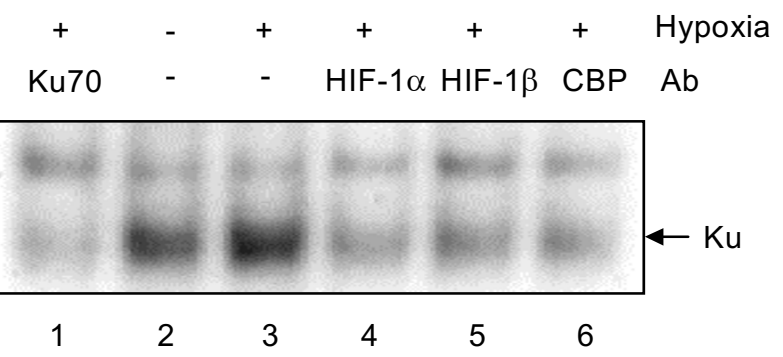

Figure 6. Analysis of interaction between HIF-1 and Ku by supershift assay. The nuclear extracts from HepaC1C7 cells treated with $260 \mu \mathrm{M}$ $D F X$ for $4 \mathrm{~h}(A$, lane 2-5) or untreated cells (A, lane 1) were isolated. For supershift assay, the nuclear extracts were preincubated with anit-Ku70 antibody (A, lane 5) or anti-CBP antibody as a positive control (A, lane 3 ) and subjected to EMSA. Also, the cells were exposed to hypoxia $(B$, lane1 and $3-6)$ for $4 \mathrm{~h}$ or normoxia $(B$, lane 2$)$, and the nuclear extracts were prepared for supershift assay using anti-HIF-1 $\alpha$ (B lane $4)$, anti-HIF1B (B, lane 5$)$, anti-CBP (B, lane 6$)$ or anti-Ku70 antibody as a positive control (B, lane 1).

PK expression and thus the expressions of HIF-1 and $\mathrm{Ku}$ appears to be involved in development of chemoresistance, we now examined whether the chemosensitivity and its modulation by DFX could differentially display in HIF-1 $\beta$-deficient HepaC4 cells, which is unable to form functional HIF-1 and concurrently have reduced $\mathrm{Ku}$ activity, and parental HepaC1C7 cells. As shown in Table 1, HepaC4 cells were more significantly susceptible to etoposide (VP16) than $\mathrm{HepaC} 1 \mathrm{C} 7$ cells. In contrast, the treatment of DFX (5- and $10 \mu \mathrm{M}$ ) with VP-16 of HepaC1C7 cells resulted in induction of approximately 7 - and 9 -fold resistance to VP-16, respectively, whereas the VP-16 sensitivity of HepaC4 cells was not changed significantly by DFX treatment. These results showed that an increased HIF-1 activity may be responsible for resistance to anticancer drug under hypoxic condition.

\section{Discussion}

HIF-1 is an attractive molecular target for development of novel cancer therapeutics. In human cancer cells, intratumoral hypoxia and genetic alterations affecting signal transduction pathways lead to increased HIF-1 activity. In this study, we revealed the involvement of the DNA-dependent protein kinase (DNA-PK) pathway in the regulation of HIF-1, and it could be implicated in resistance to cancer therapy of hypoxic tumor cells.

DNA-PK is a critical enzyme in DNA DSBs repair, and defects in DNA-PK subunits have been shown to result in hypersensitivity to ionizing radiation and etoposide that lead to DNA DSBs (Lees-Miller et al., 1995; Gu et al., 1997; Jin et al., 1998). In addition, it has been reported that $\mathrm{Ku}$ - or DNA-PKcs deficient cells are sensitive to anticancer drug including non-DNA damaging agents (Kim et al., 1999; Um et al., 2003).
Table 1. Modulation of chemosensitivity by DFX in HIF-1 $\beta$ deficient HepaC4 and wild type HepaC1C7 cells.

\begin{tabular}{lcrc}
\hline Cells & Drugs & IC $_{50}$ & $\begin{array}{c}\text { Resistance } \\
\text { induction (fold) }\end{array}$ \\
\hline HepaC1C7 & VP-16 (nM) & 45 & \\
& $+5 \mu \mathrm{M}$ DFX & 250 & 5.6 \\
& $+10 \mu \mathrm{M}$ DFX & 396 & 8.8 \\
\hline Hepa1C4 & VP-16 (nM) & 18 & \\
& $+5 \mu \mathrm{M} \mathrm{DFX}$ & 18 & 1.0 \\
& $+10 \mu \mathrm{M}$ DFX & 32 & 1.8 \\
\hline
\end{tabular}

Each cell line $\left(4 \times 10^{3}\right.$ cells/well) was treated with VP-16 for $96 \mathrm{~h}$ in the presence or absence of 5-, $10 \mu \mathrm{M}$ DFX pretreatment for 6 h. Growth inhibition assay was performed by MTT method and $I_{50}$ was determined by growth inhibition plot. Values (folds of resistance induction) indicate the ratio of $I C_{50}$ for VP-16 alone to the $I C_{50}$ for VP-16 in the presence of DFX. Values are the average of two independent experiments and triplicate determinants in each experiments. VP-16, etoposide; DFX, deferoxamine.

In the present study, HIF-1 $\beta$ deficient HepaC4 cells which are unable to form a functional HIF-1 complex (Wood et al., 1996; Maxwell et al., 1997; Griffiths et al., 2002) showed constitutively reduced $\mathrm{Ku}$ and NF$\kappa \mathrm{B}$ activities and enhanced chemosensitivity compared to parental HepaC1C7 cells, which showed the induction of drug resistance against etoposide (VP-16) under hypoxic condition, suggesting DNA-PK as well as NF-KB could be involved in HIF-1 regulation. These results were in agreement with previous reports that NF-KB is activated by hypoxia (Koong et al., 1994) and regulate HIF-1 mediated gene expression (Figueroa et al., 2002; Jeong et al., 2003; Jung et al., 2003). Also, our results showed that the increased expression and activity of DNA-PK were accompanied with an increase in HIF- $1 \alpha$ expression 
under hypoxic condition. It has been reported that hypoxia could induce chromosomal breaks at fragile sites (Coquelle et al., 1998) and HIF-1 $\alpha$ dependent repair of DNA double strand break (Unruh et al., 2003), suggesting the possibility that a DNA-PK could be activated in response to hypoxia. In fact, it has been shown that $\mathrm{Ku}$ could be involved in response to hypoxia (Ginis and Faller, 2000; Lynch et al., 2001).

In the current study, Ku- and DNA-PKcs deficient sublines showed significantly down-regulated HIF-1 $\alpha$ expression level under hypoxic condition, suggesting a possibility that DNA-PK could function as a positive regulator of the HIF-1 expression. Our results also revealed that DNA-PK complex could directly interact with HIF-1 and suggest the possibility that DNA-PKcs could be involved in phosphorylation of HIF-1. DNAPK has been known to interact and phophorylate certain transcription factors (Anderson, 1993; Bannister et al., 1993; Jackson et al., 1993; Araki et al., 1999). Although the phosphorylation domain of HIF-1 by DNA-PK is remained to be defined, several studies have reported that functionally active HIF-1 is necessary to be phosphorylated, which is important for HIF-1 mediated gene expression and the regulation of cell survival or death under hypoxia (Wang et al., 1995; Salceda et al., 1997; Minet et al., 2001; Semenza, 2002). For example, p42/p44 mitogen-activated protein kinase phosphorylate HIF-1 $\alpha$, enhancing the transcriptional activity of HIF-1 (Sang et al., 2003), and HIF- $1 \alpha$ stabilization under hypoxia is dependent on a phosphatidylinositol 3-kinase (PI3K) /Akt pathway (Minet et al, 2001). The present results suggest the possibility that the hypoxia-induced activation of DNA$\mathrm{PK}$, which belongs to the PI3K family, is associated with phosphorylation of HIF- $1 \alpha$, and it leads to HIF-1 $\alpha$ stabilization.

On the other hand, HIF-1 has been shown to mediate hypoxia-induced P-glycoprotein expression as a pathway for resistance of some tumors to chemotherapeutics (Comerford et al., 2002; Wartenberg et al., 2003) and enhanced expression of DNA-PK participates in development of multidrug resistance (MDR), which protect cancer cells from variety of drugs with different structure and function (Kim et al., 2000; Um et al., 2001). Therefore it is likely that stabilization of HIF-1 $\alpha$ by DNA-PK could be one of the multitude mechanisms in resistance to chemotherapy of hypoxic tumor cells. We revealed that expression levels of HIF-1 and DNA-PK may be mutually controlled through direct interaction. This might have a role as a negative factor for tumor therapy in hypoxic tumor cells. To elucidate the interrelated regulation between HIF-1 and DNA-PK, further investigation will be required.

Taken together, present study suggests that correlated activation of DNA-PK and HIF-1 contributes to development of chemoresistance in hypoxic tumor cells. These findings provide new therapeutic strategies in hypoxic tumor cells, which are resistant to cancer therapy such as ionizing radiation and chemotherapy.

\section{Acknowledgment}

This study was supported by a grant of the Korea Health 21 R\&D Project, Ministry of Health \& Welfare, Republic of Korea (01-PJ1-PG3-20900-0008).

\section{References}

Ader I, Muller C, Bonnet J, Favre G, Cohen-Jonathan E, Salles B, Toulas C. The radioprotective effect of the $24 \mathrm{kDa}$ FGF-2 isoform in HeLa cells is related to an increased expression and activity of the DNA dependent protein kinase (DNA-PK) catalytic subunit. Oncogene 2002;21:6471-79

Aebersold DM, Burri P, Beer KT, Laissue J, Djonov V, Greiner RH, Semenza GL. Expression of hypoxia-inducible factor-1alpha: a novel predictive and prognostic parameter in the radiotherapy of oropharyngeal cancer. Cancer Res 2001; 61:2911-16

Anderson CW. DNA damage and the DNA-activated protein kinase. Trends Biochem Sci 1993;18:433-7

Araki R, Fukumura R, Fujimori A, Taya $Y$, Shiloh $Y$, Kurimasa A, Burma S, Li GC, Chen DJ, Sato K, Hoki Y, Tatsumi K. Enhanced phosphorylation of p53 serine 18 following DNA damage in DNA-dependent protein kinase catalytic subunit-deficient cells. Cancer Res 1999;59:3543-6

Bannister AJ, Gottlieb TM, Kouzarides T, Jackson SP. c-Jun is phosphorylated by the DNA-dependent protein kinase in vitro; definition of the minimal kinase recognition motif. Nucleic Acids Res 1993;21:1289-95

Brahimi-Horn C, Berra E, Pouyssegur J. Hypoxia: the tumor's gateway to progression along the angiogenic pathway. Trends Cell Biol 2001;11:S32-6

Brown JM. Exploiting the hypoxic cancer cell: mechanisms and therapeutic strategies. Mol Med Today 2000;6:157-62

Byun MS, Jeon KI, Choi JW, Shim JY, Jue DM. Dual effect of oxidative stress on NF-KB activation in HeLa cells. Exp Mol Med 2002;34:332-9

Christodoulopoulos G, Muller C, Salles B, Kazmi R, Panasci L. Potentiation of chlorambucil cytotoxicity in B-cell chronic lymphocytic leukemia by inhibition of DNA-dependent protein kinase activity using wortmannin. Cancer Res 1998;58:178992

Comerford KM, Wallace TJ, Karhausen J, Louis NA, Montalto MC, Colgan SP. Hypoxia-inducible factor-1-dependent regulation of the multidrug resistance (MDR1) gene. Cancer Res 2002;62:3387-94

Coquelle A, Toledo F, Stern S, Bieth A, Debatisse M. A new role for hypoxia in tumor progression: induction of fragile site triggering genomic rearrangements and formation of complex 
DMs and HSRs. Mol Cell 1998;2:259-65

Figueroa YG, Chan AK, Ibrahim R, Tang Y, Burow ME, Alam $J$, Scandurro AB, Beckman BS. NF-kappaB plays a key role in hypoxia-inducible factor-1-regulated erythropoietin gene expression. Exp Hematol 2002;30:1419-27

Ginis I, Faller DV. Hypoxia affects tumor cell invasiveness in vitro: the role of hypoxia-activated ligand HAL1/13 (Ku86 autoantigen). Cancer Lett 2000;154:163-74

Goonewardene TI, Sowter HM, Harris AL. Hypoxia-induced pathways in breast cancer. Microsc Res Tech 2002;59:41-8

Gottlieb TM, Jackson SP. The DNA-dependent protein kinase: requirement for DNA ends and association with $\mathrm{Ku}$ antigen. Cell 1993;72:131-42

Griffiths JR, McSheehy PM, Robinson SP, Troy H, Chung YL, Leek RD, Williams KJ, Stratford IJ, Harris AL, Stubbs $M$. Metabolic changes detected by in vivo magnetic resonance studies of HEPA-1 wild-type tumors and tumors deficient in hypoxia-inducible factor-1beta (HIF-1beta): evidence of an anabolic role for the HIF-1 pathway. Cancer Res 2002;62:688-95

Gu Y, Jin S, Gao Y, Weaver DT, Alt FW. Ku70-deficient embryonic stem cells have increased ionizing radiosensitivity, defective DNA end-binding activity, and inability to support V(D)J recombination. Proc Natl Acad Sci USA 1997;94: 8076-81

Harris AL. Hypoxia--a key regulatory factor in tumour growth. Nat Rev Cancer 2002;2:38-47

Jackson S, Gottlieb T, Hartley K. Phosphorylation of transcription factor Sp1 by the DNA-dependent protein kinase. Adv Second Messenger Phosphoprotein Res 1993;28:279-86

Jeggo PA. DNA-PK: at the cross-roads of biochemistry and genetics. Mutat Res 1997;384:1-14

Jeong HJ, Chung HS, Lee BR, Kim SJ, Yoo SJ, Hong SH, $\mathrm{Kim} \mathrm{HM}$. Expression of proinflammatory cytokines via HIF-1alpha and NF-kappaB activation on desferrioxaminestimulated HMC-1 cells. Biochem Biophys Res Commun 2003;306:805-11

Jin S, Inoue S, Weaver DT. Functions of the DNA dependent protein kinase. Cancer Surv 1997;29:221-61

Jin $S$, Inoue $S$, Weaver DT. Differential etoposide sensitivity of cells deficient in the Ku and DNA-PKcs components of the DNA-dependent protein kinase. Carcinogenesis 1998; 19:965-71

Joung YH, Park JH, Park T, Lee CS, Kim OH, Ye SK, Yang UM, Lee KJ, Yang YM. Hypoxia activates signal transducers and activators of transcription 5 (STAT5) and increases its binding activity to the GAS element in mammary epithelial cells. Exp Mol Med 2003;35:350-7

Jung $Y$, Isaacs JS, Lee S, Trepel J, Liu ZG, Neckers L. Hypoxia-inducible factor induction by tumour necrosis factor in normoxic cells requires receptor-interacting proteindependent nuclear factor kappa B activation. Biochem J 2003;370:1011-7

Kienker LJ, Shin EK, Meek K. Both V(D)J recombination and radioresistance require DNA-PK kinase activity, though minimal levels suffice for $V(D) J$ recombination. Nucleic Acids
Res 2000;28:2752-61

Kim CH, Park SJ, Lee SH. A targeted inhibition of DNAdependent protein kinase sensitizes breast cancer cells following ionizing radiation. J Pharmacol Exp Ther 2002;303: 753-9

Kim SH, Kim D, Han JS, Jeong CS, Chung BS, Kang CD, Li GC. Ku autoantigen affects the susceptibility to anticancer drugs. Cancer Res 1999;59:4012-7

Kim SH, Um JH, Dong-Won B, Kwon BH, Kim DW, Chung BS, Kang CD. Potentiation of chemosensitivity in multidrugresistant human leukemia CEM cells by inhibition of DNAdependent protein kinase using wortmannin. Leuk Res 2000;24:917-25

Koong AC, Chen EY, Giaccia AJ. Hypoxia causes the activation of nuclear factor kappa $B$ through the phosphorylation of I kappa B alpha on tyrosine residues. Cancer Res 1994;54:1425-30

Lees-Miller SP, Godbout R, Chan DW, Weinfeld M, Day RS, 3rd, Barron GM, Allalunis-Turner J. Absence of p350 subunit of DNA-activated protein kinase from a radiosensitive human cell line. Science 1995;267:1183-5

Lim JW, Kim H, Kim KH. Expression of Ku70 and Ku80 mediated by NF-kappa B and cyclooxygenase-2 is related to proliferation of human gastric cancer cells. J Biol Chem 2002;277:46093-100

Lynch EM, Moreland RB, Ginis I, Perrine SP, Faller DV. Hypoxia-activated ligand HAL-1/13 is lupus autoantigen Ku80 and mediates lymphoid cell adhesion in vitro. Am J Physiol Cell Physiol 2001;280:C897-911

Marples B, Cann NE, Mitchell CR, Johnston PJ, Joiner MC. Evidence for the involvement of DNA-dependent protein kinase in the phenomena of low dose hyper-radiosensitivity and increased radioresistance. Int J Radiat Biol 2002;78: 1139-47

Maxwell PH, Dachs GU, Gleadle JM, Nicholls LG, Harris AL, Stratford IJ, Hankinson O, Pugh CW, Ratcliffe PJ. Hypoxia-inducible factor-1 modulates gene expression in solid tumors and influences both angiogenesis and tumor growth. Proc Natl Acad Sci USA 1997;94:8104-9

Mazure NM, Chen EY, Laderoute KR, Giaccia AJ. Induction of vascular endothelial growth factor by hypoxia is modulated by a phosphatidylinositol 3-kinase/Akt signaling pathway in Ha-ras-transformed cells through a hypoxia inducible factor-1 transcriptional element. Blood 1997;90:3322-31

Minet E, Michel G, Mottet D, Raes M, Michiels C. Transduction pathways involved in Hypoxia-Inducible Factor-1 phosphorylation and activation. Free Radic Biol Med 2001; 31:847-55

Morozov VE, Falzon M, Anderson CW, Kuff EL. DNAdependent protein kinase is activated by nicks and larger single-stranded gaps. J Biol Chem 1994;269:16684-8

Muller C, Christodoulopoulos G, Salles B, Panasci L. DNADependent protein kinase activity correlates with clinical and in vitro sensitivity of chronic lymphocytic leukemia lymphocytes to nitrogen mustards. Blood 1998;92:2213-9

Richard DE, Berra E, Gothie E, Roux D, Pouyssegur J. p42/p44 mitogen-activated protein kinases phosphorylate 
hypoxia-inducible factor 1alpha (HIF-1alpha) and enhance the transcriptional activity of HIF-1. J Biol Chem 1999; 274:32631-7

Salceda S, Beck I, Srinivas V, Caro J. Complex role of protein phosphorylation in gene activation by hypoxia. Kidney Int 1997;51:556-9

Sang N, Stiehl DP, Bohensky J, Leshchinsky I, Srinivas V, Caro J. MAPK signaling up-regulates the activity of hypoxia-inducible factors by its effects on p300. J Biol Chem 2003;278:14013-9

Semenza G. Signal transduction to hypoxia-inducible factor 1. Biochem Pharmacol 2002;64:993-8

Shen H, Schultz M, Kruh GD, Tew KD. Increased expression of DNA-dependent protein kinase confers resistance to adriamycin. Biochim Biophys Acta 1998:1381:131-8

Shintani S, Mihara M, Li C, Nakahara Y, Hino S, Nakashiro $\mathrm{K}$, Hamakawa H. Up-regulation of DNA-dependent protein kinase correlates with radiation resistance in oral squamous cell carcinoma. Cancer Sci 2003;94:894-900

Soubeyrand S, Pope L, Pakuts B, Hache RJ. Threonines $2638 / 2647$ in DNA-PK are essential for cellular resistance to ionizing radiation. Cancer Res 2003;63:1198-201

Um JH, Kang CD, Lee BG, Kim DW, Chung BS, Kim SH. Increased and correlated nuclear factor-kappa $\mathrm{B}$ and $\mathrm{Ku}$ autoantigen activities are associated with development of multidrug resistance. Oncogene 2001;20:6048-56

Um JH, Kang CD, Hwang BW, Ha MY, Hur JG, Kim DW, Chung BS, Kim SH. Involvement of DNA-dependent protein kinase in regulation of the mitochondrial heat shock proteins. Leuk Res 2003;27:509-16

Unruh A, Ressel A, Mohamed HG, Johnson RS, Nadrowitz $\mathrm{R}$, Richter $\mathrm{E}$, Katschinski DM, Wenger RH. The hypoxiainducible factor-1 alpha is a negative factor for tumor therapy. Oncogene 2003;22:3213-20
Wang GL, Jiang BH, Semenza GL. Effect of protein kinase and phosphatase inhibitors on expression of hypoxia-inducible factor 1. Biochem Biophys Res Commun 1995;216: 669-75

Wartenberg $M$, Ling FC, Muschen $M$, Klein $F$, Acker $H$, Gassmann M, Petrat K, Putz V, Hescheler J, Sauer H. Regulation of the multidrug resistance transporter P-glycoprotein in multicellular tumor spheroids by hypoxia-inducible factor (HIF-1) and reactive oxygen species. FASEB J 2003;17:503-5

Wood SM, Gleadle JM, Pugh CW, Hankinson O, Ratcliffe PJ. The role of the aryl hydrocarbon receptor nuclear translocator (ARNT) in hypoxic induction of gene expression. Studies in ARNT-deficient cells. J Biol Chem 1996;271: 15117-23

Wouters BG, Weppler SA, Koritzinsky M, Landuyt W, Nuyts S, Theys J, Chiu RK, Lambin P. Hypoxia as a target for combined modality treatments. Eur J Cancer 2002;38:240-57

Yan SF, Zou YS, Mendelsohn M, Gao Y, Naka Y, Du Yan $S$, Pinsky D, Stern D. Nuclear factor interleukin 6 motifs mediate tissue-specific gene transcription in hypoxia. $\mathrm{J}$ Biol Chem 1997;272:4287-94

Yan SF, Lu J, Zou YS, Soh-Won J, Cohen DM, Buttrick PM, Cooper DR, Steinberg SF, Mackman N, Pinsky DJ, Stern DM. Hypoxia-associated induction of early growth response-1 gene expression. J Biol Chem 1999;274:15030-40

Yao KS, Xanthoudakis S, Curran T, O'Dwyer PJ. Activation of AP-1 and of a nuclear redox factor, Ref-1, in the response of HT29 colon cancer cells to hypoxia. Mol Cell Biol 1994;14:5997-6003

Zhong $H$, De Marzo AM, Laughner E, Lim M, Hilton DA, Zagzag $D$, Buechler $P$, Isaacs WB, Semenza GL, Simons JW. Overexpression of hypoxia-inducible factor 1alpha in common human cancers and their metastases. Cancer Res 1999;59:5830-5 